\title{
The Allosteric Potentiation of Nicotinic Acetylcholine Receptors by Galantamine Ameliorates the Cognitive Dysfunction in Beta Amyloid $25-35$ I.c.v.-Injected Mice: Involvement of Dopaminergic Systems
}

\author{
Dayong Wang ${ }^{1,2,5}$, Yukihiro Noda ${ }^{1,3,5}$, Yuan Zhou ${ }^{1,4,5}$, Akihiro Mouri', Hiroyuki Mizoguchi', Atsumi Nitta', \\ Weiduo Chen ${ }^{4}$ and Toshitaka Nabeshima*,1 \\ 'Department of Neuropsychopharmacology and Hospital Pharmacy, Nagoya University Graduate School of Medicine, Nagoya, Japan; ${ }^{2}$ Division \\ of Scientific Affairs, Japanese Society of Pharmacopoeia, Tokyo, Japan; ${ }^{3}$ Division of Clinical Science and Neuropsychopharmacology in Clinical \\ Pharmacy Practice, Management and Research, Faculty of Pharmacy, Meijo University, Nagoya, Japan; ${ }^{4}$ Department of Molecular Biology, \\ College of Life Science, Northeast Agricultural University, Harbin, Heilongjiang, China
}

\begin{abstract}
Galantamine, a drug for Alzheimer's disease, is a novel cholinergic agent with a dual mode of action, which inhibits acetylcholinesterase and allosterically modulates nicotinic acetylcholine receptors (nAChRs), as a result stimulates catecholamine neurotransmission. In the present study, we investigated whether galantamine exerts cognitive improving effects through the allosteric modulation of $\mathrm{nAChR}$ in the intracerebroventricular beta amyloid $(\mathrm{A} \beta)_{25}-35$-injected animal model of Alzheimer's disease. Galantamine ( $3 \mathrm{mg} / \mathrm{kg}$ p.o.) significantly increased the extracellular dopamine release in the hippocampus of saline- and $A \beta_{25}$-35-injected mice. The effects of nicotine on the extracellular dopamine release were potentiated by galantamine, but antagonized by mecamylamine, a $n A C h R$ antagonist. $A \beta_{25-35^{-}}$ injected mice, compared with saline-injected mice, could not discriminate between new and familiar objects in the novel object recognition test and exhibited less freezing response in the fear-conditioning tasks, suggesting $A \beta_{25-35}$ induced cognitive impairment. Galantamine improved the $A \beta_{25}-35$-induced cognitive impairment in the novel object recognition and fear-conditioning tasks. These improving effects of galantamine were blocked by the treatment with mecamylamine, SCH-23390, a dopamine-DI receptor antagonist, and sulpiride, a dopamine-D2 receptor antagonist, but not by scopolamine, a muscarinic acetylcholine receptor antagonist. This study provides the first in vivo evidence that galantamine augments dopaminergic neurotransmission within the hippocampus through the allosteric potentiation of $\mathrm{nAChRs}$. The improving-effects of galantamine on the $\mathrm{A} \beta_{25-35}$-induced cognitive impairment may be mediated through the activation of, at least in part, dopaminergic systems, and the enhancement of dopamine release may be one of multiple mechanisms underlying the therapeutic benefit of galantamine.
\end{abstract}

Neuropsychopharmacology (2007) 32, I26 I - I27 I. doi: I 0. I038/sj.npp. I 30 I 256; published online 29 November 2006

Keywords: Alzheimer's disease; galantamine; nicotinic acetylcholine receptor; allosteric potentiating ligand; beta amyloid $25-35$; dopamine release

\section{INTRODUCTION}

Alzheimer's disease is a progressive and neurodegenerative disorder that is associated with a global impairment of higher mental function, with confusion, loss of memory, and impairment of cognitive function (Palmer, 2002). There

\footnotetext{
*Correspondence: Dr T Nabeshima, Department of Neuropsychopharmacology and Hospital Pharmacy, Nagoya University Graduate School of Medicine, 65 Tsuruma-cho, Showa-ku, Nagoya, Aichi-ken 466-8560, Japan, Tel: +8I 52744 2674; Fax: +8I 52744 2682,

E-mail: tnabeshi@med.nagoya-u.ac.jp

${ }^{5}$ These authors contributed equally to this work.

Received 7 June 2006; revised 6 September 2006; accepted 2 October 2006
}

is evidence that the common pathological features of the deposition of $\beta$-amyloid peptide $(\mathrm{A} \beta)$ and cholinergic degeneration may play an important role in the pathogenesis of Alzheimer's disease (Nordberg, 2001). One of the most prominent cholinergic dysfunction in Alzheimer's disease is the reduced number of nicotinic acetylcholine receptors (nAChRs) in the hippocampus and cortex, correlating well with the severity of Alzheimer's disease (Schroder et al, 1991; Burghaus and Schutz, 2000). This dysfunction results in reduced nicotinic cholinergic excitation including postsynaptic depolarization, presynaptic neurotransmitter release, and intracellular signaling.

Because Alzheimer's disease is associated with a dysfunction in nicotinic neurotransmission, a novel approach to 
drug treatment in Alzheimer's disease is the application of allosteric modulators of nAChRs, which up-modulates (potentiates) the channel activity of nAChRs in response to acetylcholine. Such properties are displayed by a novel class of nAChR ligands, named 'allosteric potentiating ligands' (APLs) (Maelicke and Albuquerque, 2000; Maelicke et al, 2000). Galantamine, an approved medication for Alzheimer's disease, has a dual mechanism of action, which inhibits acetylcholinesterase and allosterically modulates nAChR as a potent APL (Eisele et al, 1993; Santos et al, 2002). In contrast to pure agonist nicotine, the stimulation of the nAChRs by galantamine is synchronized with physiological presynaptic cholinergic activity, thereby avoiding overstimulation and desensitization, and probably leading to an optimal activation of the downstream intracellular pathways (Geerts, 2005). Galantamine augments catecholamine neurotransmission within the hippocampus by augmenting the stimulative effects of endogenous nicotinic cholinergic circuits (Sharp et al, 2004) Thus, galantamine has been demonstrated to have potential cognitive improving effects on Alzheimer's disease since the allosteric action of galantamine may be related, in part, to the stimulation of catecholamine neurotransmission in addition to its enhancing effects on cholinergic systems by inhibition of acetylcholinesterase.

In the hippocampus, a critical area involved in attention and memory, the significance of nicotinic-dopaminergic interactions for cognitive function has been well documented (Hefco et al, 2004; Levin and Simon, 1998). Some cognitive and noncognitive aspects of Alzheimer's disease arise from the dysfunction of the dopaminergic and serotonergic systems rather than the cholinergic systems (Assal and Cummings, 2002; Erkinjuntti, 2002). Acetylcholine, or its hydrolysis product choline, would activate presynaptic nAChRs, leading to a $\mathrm{Ca}^{2+}$-dependent enhancement of dopamine release (Turner, 2004). From the data mentioned above, it is very important to confirm whether galantamine can improve cognitive dysfunction of Alzheimer's disease by allosterically potentiating nicotinicdopaminergic pathway.

The present study was designed to test the hypothesis that galantamine improves cognitive dysfunction in the $\mathrm{A} \beta_{25-35^{-}}$ injected animal model of Alzheimer's disease (Maurice et al, 1996), and such cognitive improving effects of galantamine are mediated via activation of $\mathrm{nAChR}$-dopaminergic systems. We attempted to investigate: (1) whether cognitive improving effects of galantamine are mediated via nAChRs in the $\mathrm{A} \beta_{25-35}$-injected mice and (2) whether galantamine augments dopamine neurotransmission within the hippocampus by activation of nAChRs.

\section{MATERIALS AND METHODS}

\section{Subjects}

Male mice of the ICR strain (Japan SLC Inc., Shizuoka, Japan), aged 5 weeks at the beginning of experiments, were used. They were housed in plastic cages, received food (CE2; Clea Japan Inc., Tokyo, Japan) and water ad libitum, and were maintained on a 12/12-h light/dark cycle (lights on from 0800 to 2000 hours). Behavioral experiments were carried out in a sound-attenuated and air-regulated experimental room, to which mice were habituated for at least $1 \mathrm{~h}$. All experiments were performed by a blind manner and in accordance with the Guidelines for Animal Experiments of Nagoya University Graduate School of Medicine. The procedures involving animals and their care conformed to the international guidelines set out in the National Institutes of Health's Guide for the Care and Use of Laboratory Animals.

\section{Drugs}

Galantamine $\quad(4 a, 5,9,10,11,12$-hexahydro-3-methoxy-11methyl-6H-benzofuro [3a,3,2-ef] benzazepin-6-ol hydrobromide) was supplied by Janssen Pharmaceutical KK (Tokyo, Japan). (-)-Nicotine di- $[+]$ tartrate, SCH-23390 $(R(+)-7-$ chloro-8-hydroxy-3-methyl-1-phenyl- 2,3,4,5-tetrahydro$1 H$-3-benzazepine hydrochloride), $S(-)$-sulpiride, and mecamylamine were purchased from Sigma (St Louis, MO, USA). Sulpiride was initially dissolved in a minimum volume of $0.1 \mathrm{~N} \mathrm{HCl}$ and was then diluted with saline. $\mathrm{A} \beta_{25-35}$ was obtained from Wako (Osaka, Japan), and was dissolved in saline at the concentration of $3 \mathrm{mM}$ and stored at $-20^{\circ} \mathrm{C}$. The $\mathrm{A} \beta_{25-35}(3 \mathrm{mM})$ were aggregated, or 'aged', by incubating in saline at $37^{\circ} \mathrm{C}$ for 4 days according to previous report (Maurice et al, 1996).

\section{Drug Treatments}

The intracerebroventricular injection of $\mathrm{A} \beta_{25-35}$ was performed according to the protocol of Maurice et al (1996). Briefly, a microsyringe with a specially made 28gauge stainless-steel needle, $3 \mathrm{~mm}$ in length, was used for microinjection. Mice were anesthetized lightly with ether, and inserted needle unilaterally $1 \mathrm{~mm}$ to the right of the midline point equidistant from each eye, at an equal distance between the eyes and the ears and perpendicular to the plane of the skull. $\mathrm{A} \beta_{25-35}(9 \mathrm{nmol} / 3 \mu \mathrm{l})$ or saline $(3 \mu \mathrm{l})$ was delivered gradually within $30 \mathrm{~s}$. Mice exhibited normal behavior within $1 \mathrm{~min}$ after injection. The injection site was confirmed by injecting Indian ink in preliminary experiments. Neither insertion of the needle nor injection of the saline had a significant influence on survival, and behavioral responses or cognitive functions (Maurice et al, 1996).

The saline- and $\mathrm{A} \beta_{25-35}$-injected mice were administered galantamine (p.o.), mecamylamine (s.c.), $\mathrm{SCH}-23390$ (s.c.), and sulpiride (s.c.) 60,30,30, and $60 \mathrm{~min}$, respectively, before the training session of the novel object recognition and the conditioning phase of the cued and contextual fearconditioning tasks. The dosages used in the present study were referred to and converted from the clinical doses, our previous publications, and/or other related researches being done in the laboratory, and determined in the preliminary researches for this study. All compounds were systemically administered at a volume of $0.1 \mathrm{ml} / 10 \mathrm{~g}$ body weight.

\section{Behavioral Procedures}

Previous reports have shown that acute exposure of hippocampal cultures to aged $\mathrm{A} \beta_{25-35}$ induced an apoptotic-mediated neuronal toxicity during a 6-day incubation and that acute injection of aged $\mathrm{A} \beta_{25-35}$ also induced cognitive dysfunction in several learning and memory tests 
in mice (Lockhart et al, 1994). In the present study, the behavioral tests started on 6 days after $\mathrm{A} \beta_{25-35}$ injection, and were carried out sequentially according to the experimental schedule shown in Figure 1.

\section{Novel Object Recognition Test}

The task was carried out on the days 6-8 after $\mathrm{A} \beta_{25-35}$ injection according to the protocol of Nagai et al (2003) and Kamei et al (2006) with a minor modification. The experimental apparatus consisted of a Plexiglas open-field box $(40 \times 40 \times 29(\mathrm{H}) \mathrm{cm})$, the floor of which was covered with paper bedding (Japan SLC Inc., Shizuoka, Japan). The apparatus was placed in a sound-isolated room. A light bulb, fastened in the upper part of the room and cannot be seen directly by the mice, provided a constant illumination of about 40 lux at the level of the task apparatus.

The novel-object recognition task procedure consisted of three sessions: habituation, training, and retention sessions. Each mouse was individually habituated to the box, with 10 min of exploration in the absence of objects on the day 6 (habituation session). During the training session on the day 7, two objects (A and B) were placed in the back corner of the box, $10 \mathrm{~cm}$ from the side wall. A mouse was then placed in the middle front of the box and the total time spent in exploring the two objects was recorded for $10 \mathrm{~min}$ by the experimenter with two stopwatches. Exploration of an object was defined as directing the nose to the object at a distance of less than $2 \mathrm{~cm}$ and/or touching it with the nose. During the retention session on the day $8(24 \mathrm{~h}$ after the training session), the animals were placed back into the same box, in which one (eg object A) of the familiar objects used during training was replaced by a novel object $\mathrm{C}$. The animals were then allowed to explore freely for $10 \mathrm{~min}$ and the time spent exploring each object was recorded. Throughout the experiments, the objects were used in a counterbalanced manner in terms of their physical complexity and emotional neutrality. A preference index, a ratio of the amount of time spent exploring any one of the two objects (training session) or the novel object (retention session) over the total time spent exploring both objects, was used to measure cognitive function (eg $\mathrm{A}$ or $\mathrm{B} /(\mathrm{B}+\mathrm{A}) \times$ $100(\%)$ in the training session, and $\mathrm{B}$ or $\mathrm{C} /(\mathrm{B}+\mathrm{C}) \times$ $100(\%)$ in the retention session).

\section{Cued and Contextual Fear-Conditioning Tests}

The cued and contextual fear-conditioning tasks were carried out on the days 9-10 after $\mathrm{A} \beta_{25-35}$ infusion according to a previous report (Enomoto et al, 2005) with a minor modification. For measuring basal levels of freezing response (preconditioning phase), on the day 9 , mice were individually placed in a neutral cage $(23 \times 23 \times 12 \mathrm{~cm})$ for $1 \mathrm{~min}$ and then in the conditioning cage $(25 \times 31 \times 11 \mathrm{~cm})$ for $2 \mathrm{~min}$. For training (conditioning phase), mice were placed in the conditioning cage, and then a 15-s tone $(80 \mathrm{~dB})$ was delivered as a conditioned stimulus. During the last $5 \mathrm{~s}$ of the tone stimulus, a foot shock of $0.8 \mathrm{~mA}$ was delivered as an unconditioned stimulus through a shock generator (Neuroscience Idea Co. Ltd, Osaka, Japan). This procedure was repeated four times with 15-s intervals. Cued and contextual tests were carried out $24 \mathrm{~h}$ after fear conditioning on the day 10 . For the cued test, the freezing response was measured in the neutral cage for $1 \mathrm{~min}$ in the presence of a continuous tone stimulus identical with the conditioned stimulus. For the contextual test, mice were placed in the conditioning cage, and the freezing response was measured for $2 \mathrm{~min}$ in the absence of the tone and the unconditioned stimulus. The freezing response was defined as that all the paws of a mouse stayed still and stooped down with fear.

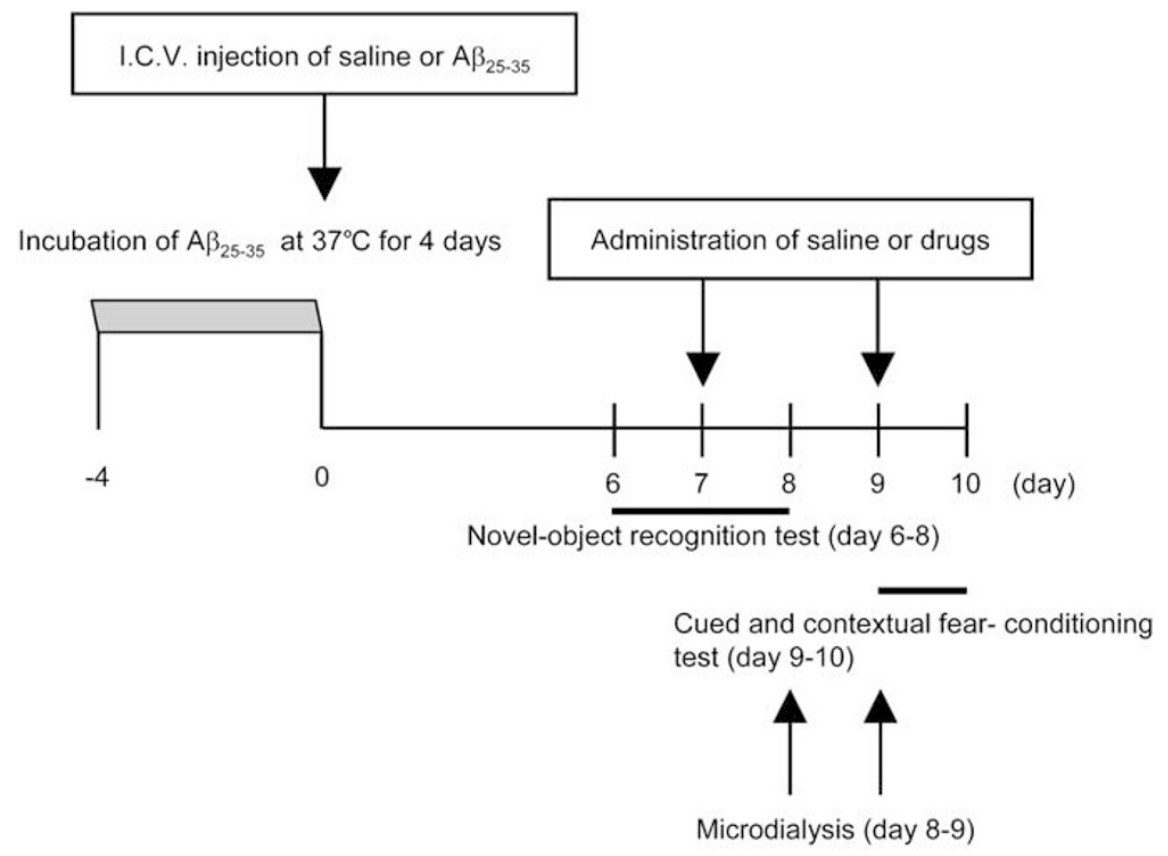

Figure I Behavioral experimental schedule. i.c.v., intracerebroventricular. 


\section{Determination of Extracellular Dopamine Levels in the Hippocampus}

We examined the effect of galantamine on the extracellular level of dopamine in the hippocampus of saline- and $\mathrm{A} \beta_{25-35}$-injected mice. At 7 or 8 days after $\mathrm{A} \beta_{25-35}$ infusion, the mice were anesthetized with sodium pentobarbital $(40 \mathrm{mg} / \mathrm{kg}$ ) and a guide cannula (MI-AG-4; Eicom, Kyoto, Japan) was implanted into the hippocampus (coordinates: anteroposterior (AP): $+3.05 \mathrm{~mm}$, mediolateral (ML): + $3.03 \mathrm{~mm}$ from bregma, dorsoventral (DV): $2.00 \mathrm{~mm}$ from the skull), according to the atlas of Paxinos and Franklin (2004). At 8 or 9 days after $\mathrm{A} \beta_{25-35}$ infusion $(24 \mathrm{~h}$ after the implantation of the guide cannula), the dialysis probe (A-I4-02; membrane length $2 \mathrm{~mm}$, Eicom) was implanted into the hippocampus and perfused with Ringer's solution $\left(147 \mathrm{mM} \mathrm{NaCl}, 4 \mathrm{mM} \mathrm{KCl}\right.$, and $2.3 \mathrm{mM} \mathrm{CaCl}_{2}$ ) at a flow rate of $1.2 \mu \mathrm{l} / \mathrm{min}$. The outflow fractions were collected every $10 \mathrm{~min}$. After the collection of three stable baseline fractions, mice were treated with galantamine, nicotine, and/or mecamylamine, and the dialysates were collected every $10 \mathrm{~min}$ for $90 \mathrm{~min}$. Dopamine levels in the dialysates were assayed by HPLC equipped with Eicompak PP-ODS column and electrochemical detector (ECD-300, Eicom).

\section{Statistical Analysis}

Results are expressed as means \pm SEM. Statistical difference among the experimental groups was tested using one-way analysis of variance (ANOVA) for behavioral tests or twoway ANOVA for microdialysis, and Tukey-Kramer post hoc test was employed for multiple comparisons. $P$-values less than 0.05 were accepted as significant.

\section{RESULTS}

\section{Effects of Galantamine on the Impairments of Performance in Novel Object Recognition and Cued/Contextual Fear-Conditioning Tasks in the $A \beta_{25-35}$-Injected Mice}

During the training session of the novel object recognition task, saline- and $\mathrm{A} \beta_{25-35}$-injected mice treated with saline or galantamine ( 1 and $3 \mathrm{mg} / \mathrm{kg}$ ) spent equal amount of time in exploring either of the two objects (Figure 2a), and thus there was no biased exploratory preference in the five groups without affecting total exploring time in the exploration of the objects (data not shown). When retention performance was tested $24 \mathrm{~h}$ after the training session, the a

Training session
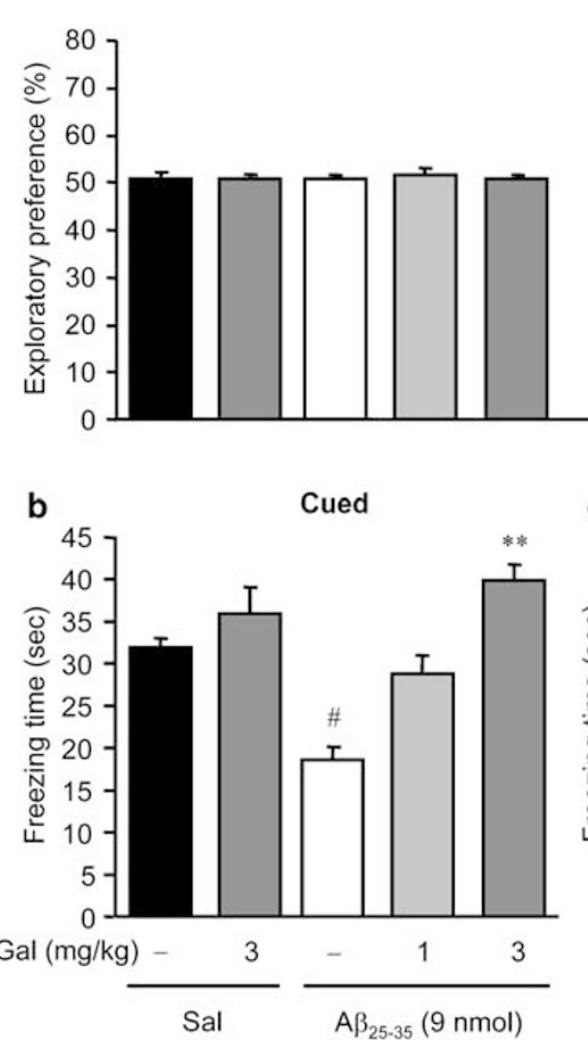

Retention session

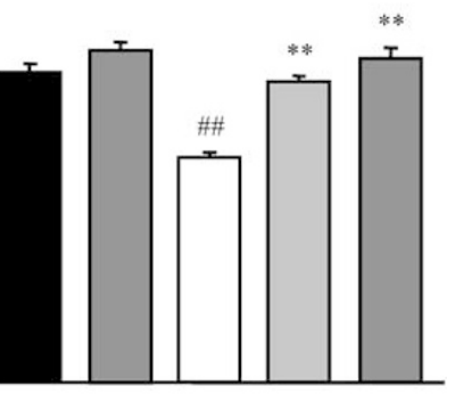

C Contextual

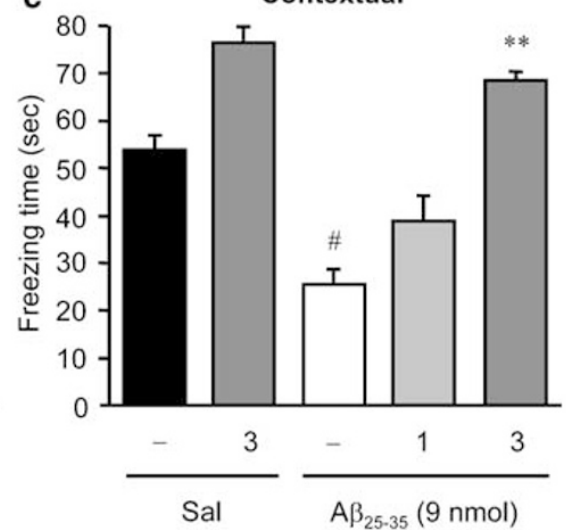

Figure 2 Effects of galantamine on behavioral deficits in $A \beta_{25}-35$-injected mice in novel object recognition, and cued and contextual fear-conditioning tasks. Galantamine ( $\mathrm{l}$ and $3 \mathrm{mg} / \mathrm{kg}$ p.o.) was administrated to saline- and $\mathrm{A} \beta_{25-35}(9 \mathrm{nmol} / 3 \mu \mathrm{l})$-injected mice 60 min before the training session of the novel object recognition task and the conditioning phase of the cued and contextual fear-conditioning tasks. (a) Novel object recognition task. In training session, $F(3,6 I)=0.14(p=0.94)$. In retention session, $F(3,6 I)=27.44(p<0.0 I)$. (b) Cued conditioning task, $F(3,6 I)=8.68(p<0.0 I)$. (c) Contextual conditioning task, $F(3,61)=6.97(p<0.01)$. Results were expressed as means \pm SEM $(n=13-17)$, and analyzed by a one-way ANOVA, followed by Tukey-Kramer test for multiple comparisons. ${ }^{\#} p<0.05,{ }^{\#} p<0.01$ vs saline-treated, saline-injected mice; ${ }^{*} * p<0.01$ vs saline-treated, $A \beta_{25}-35$-injected mice. 
level of exploratory preference for the novel object in the saline-treated $\mathrm{A} \beta_{25-35}$-injected mice was significantly decreased compared to that in the saline-treated, salineinjected mice $(p<0.01$ by post hoc (Figure 2a)). Galantamine ( 1 and $3 \mathrm{mg} / \mathrm{kg})$-treated $\mathrm{A} \beta_{25-35}$-injected mice spent a significantly longer time in exploring novel object than the saline-treated $\mathrm{A} \beta_{25-35}$-injected mice ( $p<0.01$ by post hoc) (Figure 2a), indicating that galantamine improved the recognition of novelty in mice impaired by $\mathrm{A} \beta_{25-35}$ infusion.

In the preconditioning phase of the cued and contextual fear-conditioning task, the saline- and $\mathrm{A} \beta_{25-35}$-injected mice treated with saline or galantamine $(1$ and $3 \mathrm{mg} / \mathrm{kg}$ ) hardly showed the freezing response (data not shown), and there were no differences in the basal levels of freezing response among the five groups (data not shown). In the cued and contextual fear-testing trial, saline-treated, salineinjected mice exhibited marked cued and contextual freezing response, indicating that the associative learning ability in these mice is better than that in saline-treated $\mathrm{A} \beta_{25-35}$-injected mice, which showed a significant decrease of cued and contextual freezing response $24 \mathrm{~h}$ after fear conditioning ( $p<0.01$ by post hoc) (Figure $2 \mathrm{~b}$ and $\mathrm{c}$ ). The performance of saline-treated, $\mathrm{A} \beta_{25-35}$-injected mice was completely reversed by the treatment with galantamine at the dose of $3 \mathrm{mg} / \mathrm{kg}$, but not $1 \mathrm{mg} / \mathrm{kg}$ (Figure $2 \mathrm{~b}$ and c).
Galantamine $(3 \mathrm{mg} / \mathrm{kg})$ tended to increase the cognition in both asks in saline-injected mice, but not significant. No alterations of nociceptive response were found in all the groups: the minimal current required to elicit flinching/ running, jumping, or vocalization was same in all the groups (data not shown). As galantamine ( 1 and $3 \mathrm{mg} / \mathrm{kg}$ ) significantly improved the $\mathrm{A} \beta_{25-35}$-induced cognitive impairment in dose-dependent manner, the dose of $3 \mathrm{mg} / \mathrm{kg}$ was used in subsequent experiments.

\section{Antagonistic Effects of Mecamylamine, an nAChR Antagonist, on the Cognitive Improving Effects of Galantamine in the $\mathbf{A} \boldsymbol{\beta}_{25-35}$-Injected Mice}

To determine whether the improving effects of galantamine on $\mathrm{A} \beta_{25-35}$-induced cognitive impairments are mediated via nAChRs, we examined the antagonism by mecamylamine, an nAChRs antagonist, against the cognitive improving effects of galantamine in $\mathrm{A} \beta_{25-35}$-injected mice.

In the training session of the novel object recognition task or the preconditioning phase of cued/contextual fearconditioning tasks, there were no differences in the exploratory preference for the objects or the basal levels of freezing response, respectively, among all the groups. Galantamine $(3 \mathrm{mg} / \mathrm{kg})$ improved cognitive dysfunction in novel object recognition and tone cue- and context- a

Training session

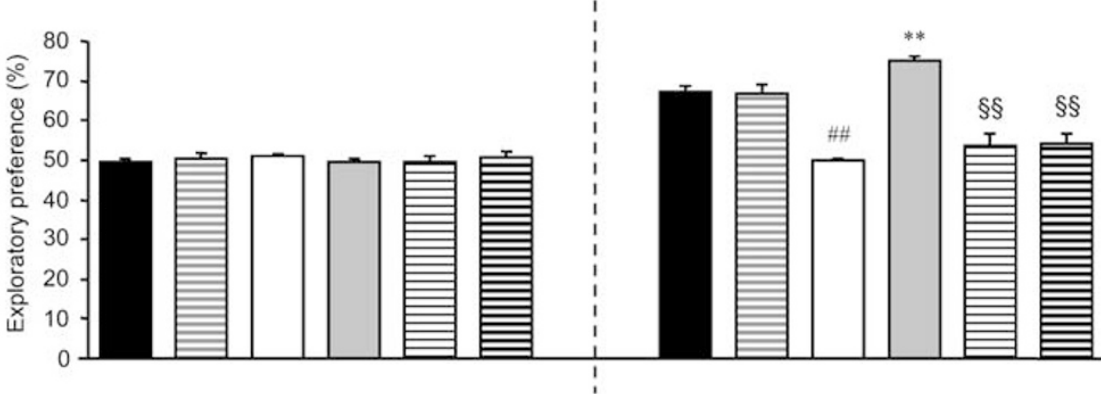

b

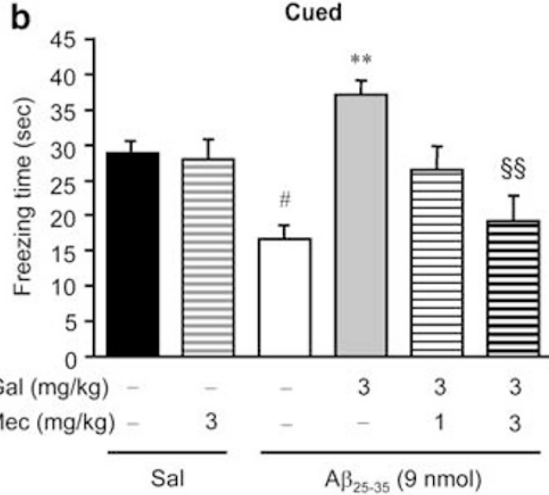

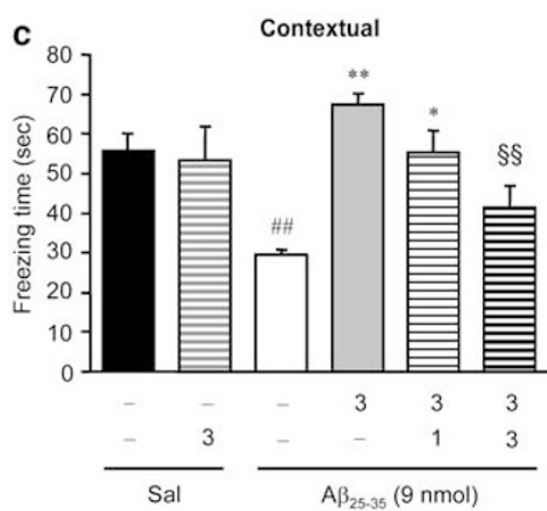

Figure 3 Antagonistic effects of mecamylamine, an $n A C h R$ antagonist, on cognitive improving effects of galantamine in $A \beta_{25-35}$-injected mice. Galantamine (3 mg/kg p.o.) and mecamylamine (Mec: I and $3 \mathrm{mg} / \mathrm{kg}$ ) were administrated to saline- and $\mathrm{A} \beta_{25-35}(9 \mathrm{nmol} / 3 \mu \mathrm{l})$-injected mice 60 and $30 \mathrm{~min}$, respectively, before the training session of novel object recognition task and the conditioning phase of cued and contextual fear-conditioning tasks. (a) Novel object recognition task. In training session, $F(5,63)=0.32(p=0.90)$. In retention session, $F(5,63)=25.83$ ( $p<0.0 \mathrm{I})$. (b) Cued conditioning task, $F(5,63)=7.73(p<0.0 \mathrm{I})$. (c) Contextual conditioning task, $F(5,63)=7.90(p<0.0 \mathrm{I})$. Results were expressed as means \pm SEM $(n=8-I 2)$, and analyzed by a one-way ANOVA, followed by Tukey-Kramer test for multiple comparisons. ${ }^{*} p<0.05,{ }^{\#} p<0.01$ vs saline-treated, saline-injected mice; ${ }^{* *} p<0.0$ I vs saline-treated, $A \beta_{25-35}$-injected mice; ${ }^{\$ \S} p<0.0$ I vs galantamine-treated, $A \beta_{25}-35$-injected mice. Sal, saline; Gal, galantamine; Mec, mecamylamine. 
conditioned fear-learning tasks in $\mathrm{A} \beta_{25-35}$-injected mice. The nAChR antagonist mecamylamine $(3 \mathrm{mg} / \mathrm{kg})$ significantly and completely blocked the improving effects of galantamine on the impairment of recognition $(p<0.01$ by post hoc, Figure 3a) and cued/contextual-dependent fear learning $(p<0.01$ by post hoc, Figure $3 \mathrm{~b}$ and $c)$ in the $\mathrm{A} \beta_{25-35}$-injected mice. In saline-injected mice, mecamylamine $(3 \mathrm{mg} / \mathrm{kg})$ by itself had no effect on the novel object recognition and cued/contextual fear-conditioning performances (Figure 3).

\section{Effects of Scopolamine, a Muscarinic Receptor Antagonist, on the Cognitive Improving Effects of Galantamine in the $A \boldsymbol{\beta}_{25-35}$-Injected Mice}

To determine whether muscarinic receptors are involved in the effects of galantamine on the performance of $\mathrm{A} \beta_{25-35^{-}}$ injected mice in the cognitive tasks, the muscarinic receptor antagonist, scopolamine $(0.1$ and $0.2 \mathrm{mg} / \mathrm{kg})$, was s.c. injected to the mice $30 \mathrm{~min}$ after the p.o. administration of galantamine $(3 \mathrm{mg} / \mathrm{kg})$. Scopolamine at the dose of $0.2 \mathrm{mg} / \mathrm{kg}$ impaired the performance of saline-i.c.v.-injected mice in both novel object recognition and tone cue- and context-conditioned fear-learning tasks (Figure $4 \mathrm{a}-\mathrm{c}$ ). Galantamine $(3 \mathrm{mg} / \mathrm{kg})$ improved cognitive dysfunction in novel object recognition and tone cue- and contextconditioned fear-learning tasks in $\mathrm{A} \beta_{25-35}$-injected mice. In the novel object recognition test, scopolamine $(0.1$ and $0.2 \mathrm{mg} / \mathrm{kg}$ ) failed to prevent the effect of galantamine $(3 \mathrm{mg} /$ $\mathrm{kg}$ ) (Figure $4 \mathrm{a})$. In the cued and contextual conditioning tasks, the effects of galantamine $(3 \mathrm{mg} / \mathrm{kg})$ were not significantly prevented by scopolamine at the dosage that induces behavioral impairments in the task in saline-i.c.v.injected mice (Figure $4 \mathrm{~b}$ and $\mathrm{c}$ ). In order to well understand the effects of scopolamine on the performance of mice in these tasks, we added the galantamine $(3 \mathrm{mg} / \mathrm{kg})$-treated and galantamine $(3 \mathrm{mg} / \mathrm{kg}) / \mathrm{scopolamine}(0.2 \mathrm{mg} / \mathrm{kg})$-treated saline-i.c.v.-injected control groups. Scopolamine $(0.2 \mathrm{mg} /$ $\mathrm{kg}$ ) failed to affect the performance in the novel object recognition task in galantamine-treated mice (Figure 4a). In the cued and contextual conditioning tasks, there is the tendency to inhibit the performance in galantamine $(3 \mathrm{mg} /$ $\mathrm{kg}$ )-treated mice by scopolamine $(2 \mathrm{mg} / \mathrm{kg})$, but not significant (Figure $4 \mathrm{~b}$ and $\mathrm{c}$ ). Although the effects of galantamine was not significantly prevented by scopolamine in the cued and contextual conditioning tasks, the performance of mice is more sensitive to scopolamine in this task than in the novel object recognition task (Figure $4 \mathrm{a}-\mathrm{c}$ ).

\section{Effects of Galantamine on the Extracellular Dopamine} Level in the Hippocampus of the Saline- and $A \beta_{25-35^{-}}$ Injected Mice

We examined whether galantamine at the dose of $3 \mathrm{mg} / \mathrm{kg}$, which ameliorated the cognitive dysfunction in the $\mathrm{A} \beta_{25-35^{-}}$ injected mice, facilitated the dopamine release in the hippocampus of saline- and $\mathrm{A} \beta_{25-35}$-injected mice.

As shown in Figure 5a, the basal extracellular level of dopamine in the hippocampus of $\mathrm{A} \beta_{25-35}$-injected mice
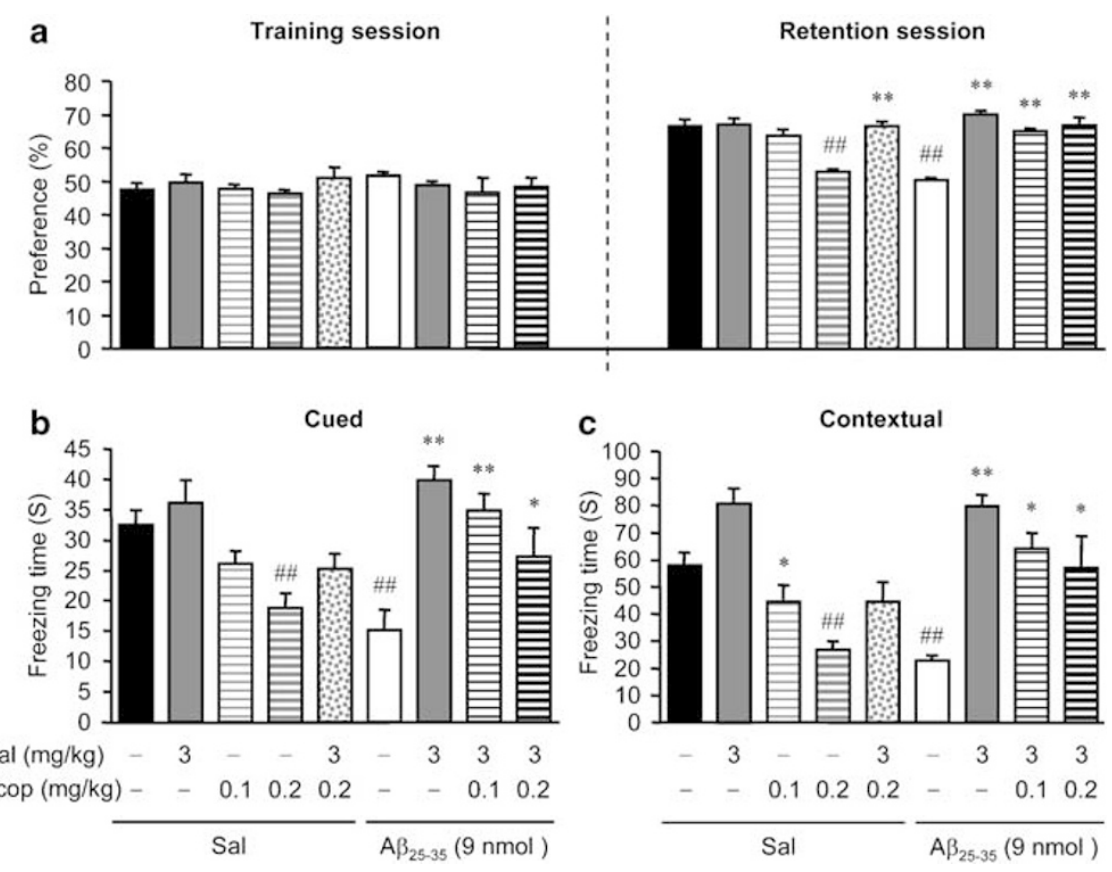

Figure 4 Effects of scopolamine, a muscarinic antagonist, on cognitive improving effects of galantamine in A $\beta_{25}-35$-injected mice. Galantamine (Gal: 3 mg/ $\mathrm{kg}$ p.o.) and scopolamine (Scop: 0.1 and $0.2 \mathrm{mg} / \mathrm{kg}$ ) were administrated to saline- and $\mathrm{A} \beta_{25-35}(9 \mathrm{nmol} / 3 \mu \mathrm{l})$-injected mice 60 and 30 min, respectively, before the training session of novel object recognition task and the conditioning phase of cued and contextual fear-conditioning tasks. (a) Novel object recognition task. In training session, $F(5,63)=0.32(p=0.90)$. In retention session, $F(8,90)=60.10(p<0.01)$. (b) Cued conditioning task, $F(8,90)=5.33$ $(p<0.0 \mathrm{I})$. (c) Contextual conditioning task, $F(8,90)=8.04(p<0.0 \mathrm{I})$. Results were expressed as means \pm SEM $(n=8-12)$, and analyzed by a one-way ANOVA, followed by Tukey-Kramer test for multiple comparisons. ${ }^{\# \#} p<0.01$ vs saline-treated saline-injected mice; ${ }^{*} p<0.05$, ** $p<0.01$ vs saline-treated, A $\beta_{25-35}$-injected mice. Sal, saline; Gal, galantamine; Scop, scopolamine. 
were significantly decreased compared to that of salineinjected mice. Galantamine $(3 \mathrm{mg} / \mathrm{kg})$ caused a marked increase in the extracellular level of dopamine in the hippocampus of saline- (Figure $5 \mathrm{~b}$ ) and $\mathrm{A} \beta_{25-35}$-injected mice (Figure $5 \mathrm{c}$ ). The significant increase in the extracellular level of dopamine was observed from about $20 \mathrm{~min}$ after galantamine administration $(p<0.01$ by post hoc, Figure $5 b$ and $c)$. When mecamylamine $(3 \mathrm{mg} / \mathrm{kg})$ was injected to saline- and $\mathrm{A} \beta_{25-35}$-injected mice $30 \mathrm{~min}$ after galantamine administration, the galantamine-induced elevation of extracellular dopamine levels was significantly diminished (Figure $5 \mathrm{~b}$ and $\mathrm{c}$ ). However, mecamylamine by itself did not significantly affect the extracellular dopamine levels in the saline- and $\mathrm{A} \beta_{25-35}$-injected mice (Figure $5 \mathrm{~b}$ and $\mathrm{c}$ ).
To confirm that dopamine release is facilitated through nAChR stimulation by galantamine, we measured extracellular dopamine level induced by nicotine in combination with galantamine in the hippocampus of $\mathrm{A} \beta_{25-35}$-injected mice. The individual administration with nicotine at the dose of $0.4 \mathrm{mg} / \mathrm{kg}$ or galantamine at the dose of $1 \mathrm{mg} / \mathrm{kg}$ does not affect the extracellular level of dopamine in the hippocampus of $\mathrm{A} \beta_{25-35}$-injected mice, However, the combination of nicotine $(0.4 \mathrm{mg} / \mathrm{kg})$ with galantamine $(1 \mathrm{mg} / \mathrm{kg})$ significantly increased the extracellular level of dopamine in the hippocampus of $\mathrm{A} \beta_{25-35}$-injected mice (Figure 6). The potentiating effect of galantamine on dopamine release was antagonized by mecamylamine $(3 \mathrm{mg} / \mathrm{kg})$ administration (Figure 6). The synergistic effects of nicotine and galantamine at low doses, and the fact that
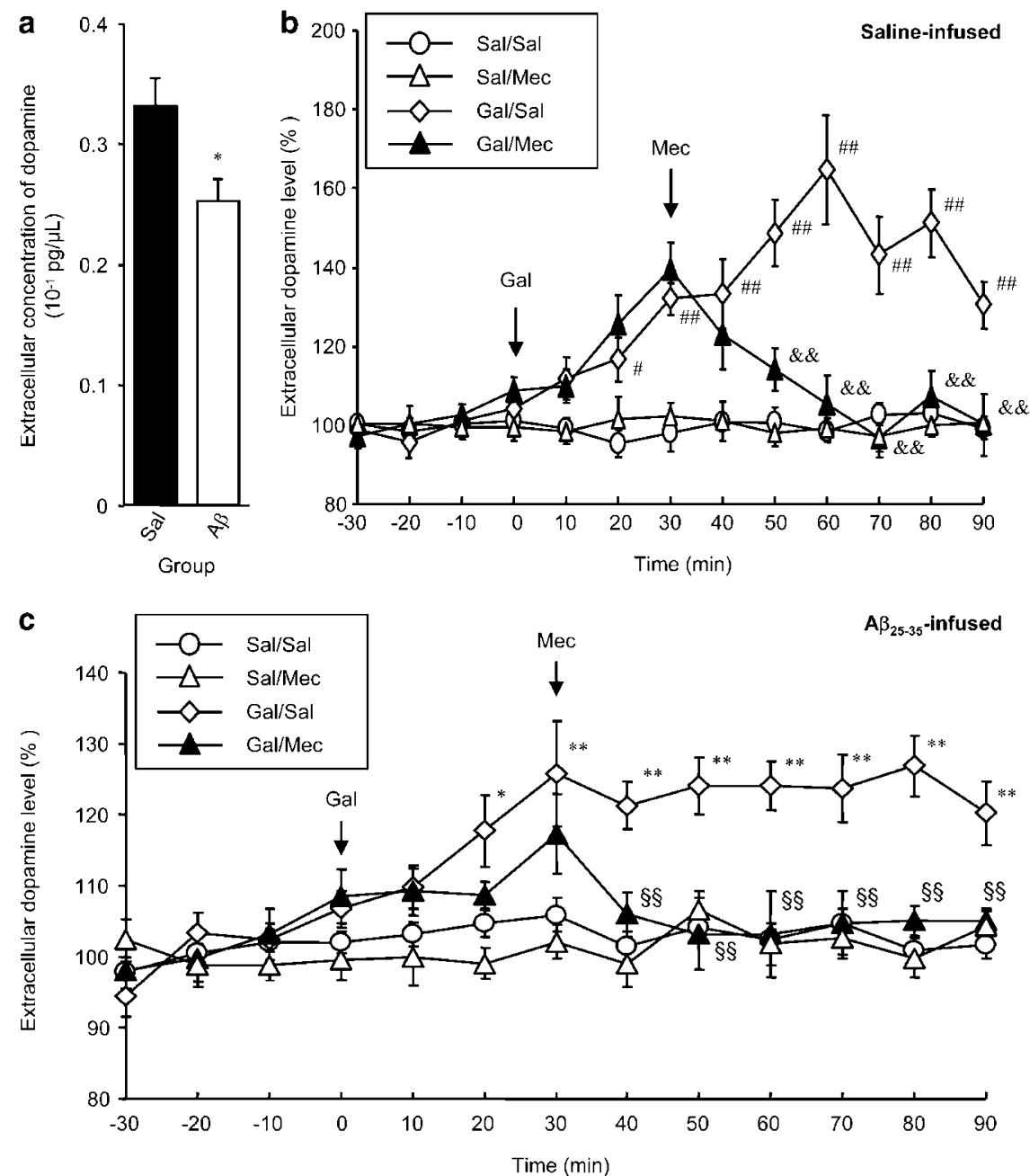

Figure 5 Effects of galantamine on extracellular dopamine level in the hippocampus of saline- and $A \beta_{25-35}$-injected mice. At 8 or 9 days after $A \beta_{25-35}$ infusion ( $24 \mathrm{~h}$ after the implantation of the guide cannula), the dialysis probe was implanted into the hippocampus. Saline- and $A \beta_{25-35}$-injected mice were treated with galantamine (Gal: $3 \mathrm{mg} / \mathrm{kg}$ p.o.) and/or mecamylamine (Mec: $3 \mathrm{mg} / \mathrm{kg}$ s.c.), and dialysates were collected every $10 \mathrm{~min}$ for $90 \mathrm{~min}$. Dopamine levels in the dialysates were assayed by HPLC with electrochemical detection. (a) Spontaneous extracellular dopamine levels in the hippocampus of salineand $A \beta_{25-35}$-injected mice. Results were expressed as means $\pm S E M, n=8$. ${ }^{*} p<0.05$ vs saline-i.c.v.-injected mice, by Student's $t$-test. (b) Effects of galantamine on extracellular dopamine level in the hippocampus of saline-injected mice. Results were expressed as means \pm SEM, $n=5-8$, and analyzed by a two-way ANOVA, followed by Tukey-Kramer test for multiple comparisons, $F_{\text {time }}(I 2,259)=3.74(p<0.01)$; $F_{\text {group }}(3,259)=37.7 \mathrm{I}(p<0.01)$. (c) Effects of galantamine on the extracellular dopamine level in the hippocampus of $\mathrm{A} \beta_{25}-35^{-i n j e c t e d ~ m i c e . ~ R e s u l t s ~ w e r e ~ e x p r e s s e d ~ a s ~ m e a n s ~} \pm$ SEM, $n=5-8$, and analyzed by a two-way ANOVA, followed by Tukey-Kramer test for multiple comparisons, $F_{\text {time }}(I 2,324)=5.79(p<0.0 I) ; F_{\text {group }}(3,324)=50.62(p<0.0 I)$. ${ }^{\#} p<0.05,{ }^{\# \#} p<0.01$ vs saline-treated saline-injected mice. ${ }^{\text {\& }} p<0.01$ vs galantamine-treated saline-injected mice. ${ }^{\#} p<0.05$, \#\# $p<0.01$ vs saline-treated, $\mathrm{A} \beta_{25-35}$-injected mice; ${ }^{\S \S} \mathrm{p}<0.01$ vs galantamine-treated, $\mathrm{A} \beta_{25-35}$-injected mice. Sal, saline; Gal, galantamine; Mac, mecamylamine. 
the synergy was antagonized by mecamylamine, indicated that galantamine indeed potentiates an nAChR-mediated effect.

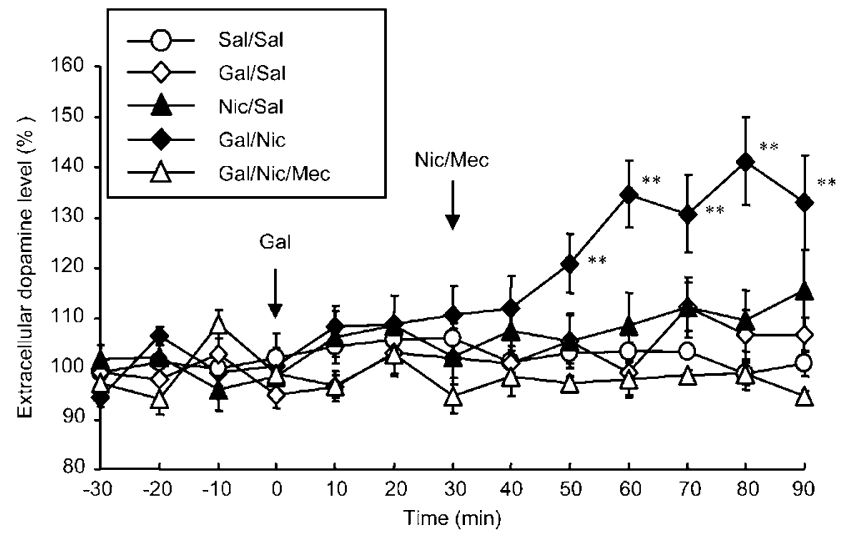

Figure 6 Effects of combined treatment with nicotine and galantamine at their non-effective doses on extracellular dopamine level in the hippocampus of $A \beta_{25-35}$-injected mice. $A \beta_{25-35}$-injected mice were administered nicotine (Nic: $0.4 \mathrm{mg} / \mathrm{kg}$ s.c.) and mecamylamine (Mec: $3 \mathrm{mg} / \mathrm{kg}$ s.c.) $30 \mathrm{~min}$ after galantamine (Gal: I mg/kg, p.o.) treatment, and dialysates were collected every 10 min for 90 min. Results were expressed as means \pm SEM, $n=5-8$, and analyzed by a two-way ANOVA, followed by Tukey-Kramer test for multiple comparisons, $F_{\text {time }}(12,376)=4.56$ $(p<0.0 I) ; F_{\text {group }}(3,376)=22.7 I \quad(p<0.01)$. *** $p<0.01$ vs saline-treated $\mathrm{A} \beta_{25-35}$-injected mice.
Involvement of Dopaminergic Systems in the Cognitive Improving Effects of Galantamine in $\mathrm{A} \boldsymbol{\beta}_{25-35}$-Injected Mice

To clarify whether the improving effects of galantamine on $\mathrm{A} \beta_{25-35}$-induced cognitive impairments are mediated through the activation of dopamine receptors, we investigated the antagonism of the cognitive improving effects of galantamine on $\mathrm{A} \beta_{25-35}$-injected mice by $\mathrm{SCH}-23390$, a dopamine-D1 receptor antagonist, and sulpiride, a dopamine-D2 receptor antagonist.

$\mathrm{SCH}-23390(0.02 \mathrm{mg} / \mathrm{kg})$ and sulpiride $(12.5 \mathrm{mg} / \mathrm{kg})$ significantly and completely antagonized the improving effects of galantamine on $\mathrm{A} \beta_{25-35}$-induced cognitive impairment without affecting the exploratory preference for the objects in the training session of the novel object recognition task. SCH-23390 and sulpiride showed no effect on the total exploration time in either the training or retention sessions of the novel object recognition task. In addition, SCH-23390 and sulpiride by themselves had no effect on novel object recognition performance in saline-injected mice (Figure 7a).

SCH-23390 $(0.02 \mathrm{mg} / \mathrm{kg})$ and sulpiride $(12.5 \mathrm{mg} / \mathrm{kg})$ significantly blocked the ameliorating effects of galantamine on the impairments of both cued and contextual fear conditioning induced by infusion of $\mathrm{A} \beta_{25-35}$. SCH-23390 and sulpiride by themselves had no effects on the cued and contextual freezing response in saline-injected mice (Figure $7 b$ and $c$ ).
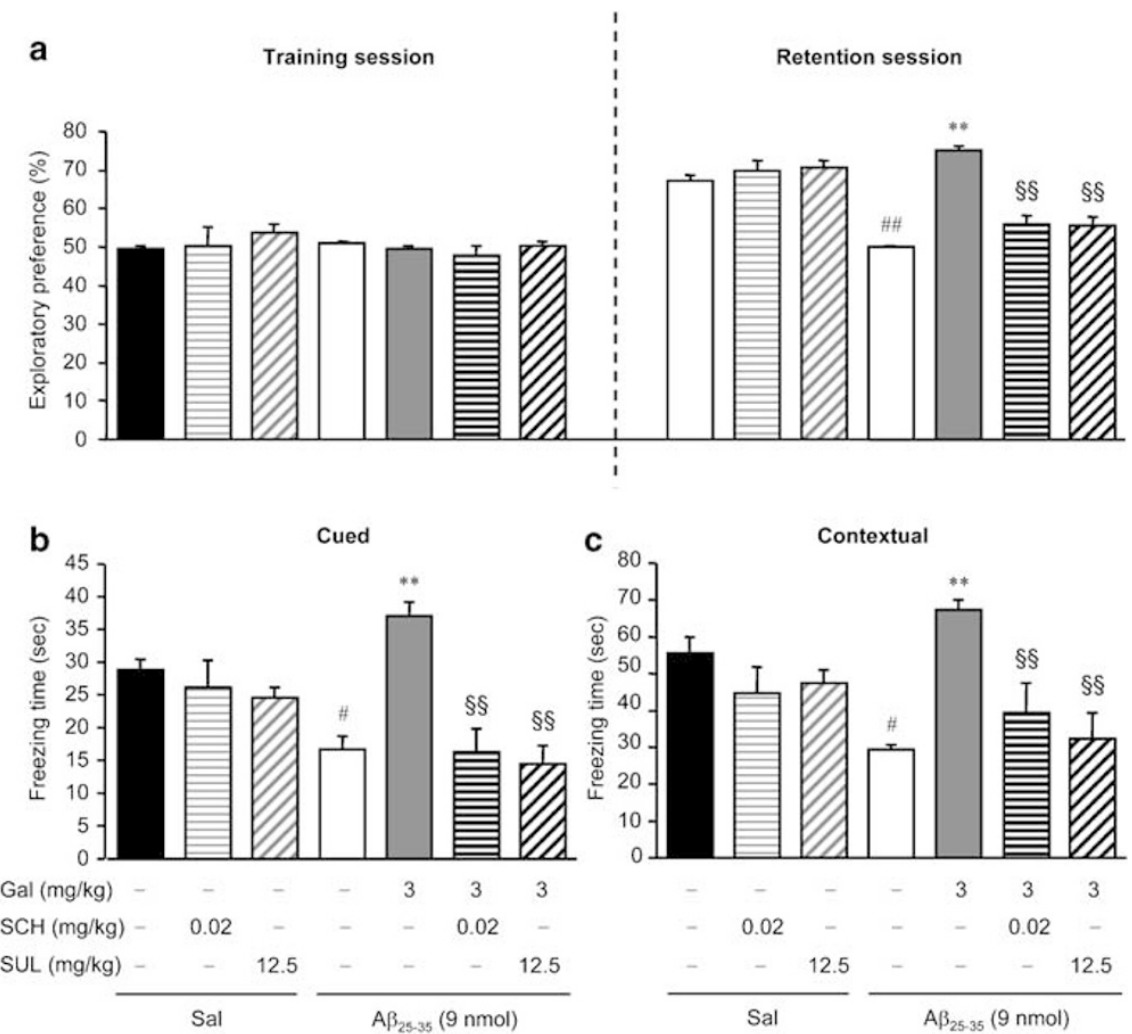

Figure 7 Involvement of dopaminergic systems in the cognitive improving effects of galantamine in $\mathrm{A} \beta_{25-35}$-injected mice. Galantamine (p.o.), SCH23390 (s.c.) and sulpiride (s.c.) were administrated to saline- and $A \beta_{25-35}(9 \mathrm{nmol} / 3 \mu \mathrm{l})$-injected mice 60,30 and 60 min respectively before the training session of novel object recognition task, and the conditioning phase of cued and contextual fear-conditioning task. (a) Novel-object recognition task. In training session, $F(6,72)=0.73(p=0.63)$. In retention session, $F(6,72)=27.13(p<0.0 I)$. (b) Cued conditioning task. $F(6,72)=9.61 \quad(p<0.01)$. (c) Contextual conditioning task. $F(6,72)=6.36(p<0.0 I)$. Results were expressed as means $\pm S E M, n=8-12$, and analyzed by a one-way ANOVA, followed by Tukey-Kramer test for multiple comparisons. ${ }^{\#} p<0.05,{ }^{\# \#} p<0.01$ vs saline-treated saline-injected mice; $*$ ** $p<0.0$ I vs saline-treated $A \beta_{25}-35^{-i n j e c t e d ~}$ mice; ${ }^{\$ \$_{p}}<0.0$ I vs galantamine-treated $\mathrm{A} \beta_{25}-35$-injected mice. Sal: saline, Gal: galantamine, SCH: SCH-23390, SUL: sulpiride. 


\section{DISCUSSION}

We found that $\mathrm{A} \beta_{25-35}$ infusion impaired novelty-discriminating ability in the novel object recognition task and associative learning and memory in the fear-conditioning tasks. It is unlikely that the impairment of performance of the $\mathrm{A} \beta_{25-35}$-injected mice in these tasks is due to changes in motivation or sensorimotor function, as various motivations are involved in these behavioral tasks, and different skills are required for better performance in each task. Actually, there was no difference of the total exploration time in the training session of novel object recognition task and freezing response in preconditioning phase of cued and contextual fear-conditioning tasks between the saline- and $\mathrm{A} \beta_{25-35}$-injected mice, indicating no changes in motor function and exploratory activity. In addition, no difference in pain threshold was found between the saline- and $\mathrm{A} \beta_{25-35}$-injected mice. Therefore, the impairment of performance in the $\mathrm{A} \beta_{25-35}$-injected mice is due to learning and memory deficits.

Galantamine, a medication for Alzheimer's disease, has a dual mechanism of action, which inhibits acetylcholinesterase and allosterically modulates $\mathrm{nAChR}$ as a potent APL (Eisele et al, 1993; Santos et al, 2002). Previous paper has reported that galantamine reverses $\mathrm{nAChR}$ antagonistinduced deficits in delay classical conditioning of the eye blink reflex in young rabbits (Woodruff-Pak et al, 2003) and impairment of spatial accuracy of APP23 transgenic mouse during probe trial of Morris water maze (Van Dam and De Deyn, 2006). In the present study, galantamine significantly ameliorated the cognitive impairments induced by $\mathrm{A} \beta_{25-35}$ infusion in the novel object recognition and fear-conditioning tasks. Galantamine at $3 \mathrm{mg} / \mathrm{kg}$ had no effect on the total exploration time in the training session of novel object recognition task and freezing response in preconditioning phase of cued and contextual fear-conditioning tasks, and sensitivity to electric footshock in the fear-conditioning phase of cued and contextual fear-conditioning tasks in the $\mathrm{A} \beta_{25-35}$-injected mice. Therefore, it is unlikely that the observed improvement of performance by galantamine in both tasks is due to changes in sensorimotor function and/or motivation in the $\mathrm{A} \beta_{25-35}$-injected mice, and it is apparently valid that galantamine ameliorates learning and memory deficits caused by the infusion of $\mathrm{A} \beta_{25-35}$ into the cerebral ventricle in mice. The improving effects of galantamine on the performance of $\mathrm{A} \beta_{25-35}$-injected mice were prevented by the treatment with mecamylamine, an nAChR antagonist, at the dose that did not significantly affect the performance of saline-i.c.v.-injected mice. These findings support the notion that galantamine improves $\mathrm{A} \beta_{25-35}$-induced cognitive impairment via activation of nAChRs. The roles of muscarinic receptors in the effects of galantamine were also investigated in the present study. The effects of galantamine on the performance of $\mathrm{A} \beta_{25-35^{-}}$ injected mice in the novel object recognition task were not prevented by scopolamine at the dose which impaired the performance of saline-i.c.v.-injected mice. This indicated that muscarinic receptors are not very important for effects of galantamine on this cognitive task. Our conclusion is supported by the reports that there is only $1-12 \%$ brain AChE inhibition $1 \mathrm{~h}$ after s.c. injection of $3 \mathrm{mg} / \mathrm{kg}$ galantamine (Geerts et al, 2005), and that galantamine is an
nAChR-allosteric modulator (Eisele et al, 1993; Santos et al, 2002). In other words, although the brain concentration of acetylcholine is only weakly increased by galantamine at the dose of $3 \mathrm{mg} / \mathrm{kg}$, it shows effects mainly by allosterically modulating the function of nAChR. Our results also indicated that the potentiation of the $\mathrm{nAChR}$ function can compensate the hypofunction of muscarinic receptors in the present cognitive tasks, especially in the novel object recognition task. As scopolamine at a dose of $0.2 \mathrm{mg} / \mathrm{kg}$ showed some effect, but not significant, on the performance of galantamine-treated mice in the cued and contextual conditioning tasks, it was indicated that muscarinic receptors may differentially regulate the observed effects of galantamine, depending on specific behavioral tasks. Although mecamylamine blocks the effects of galantamine more strongly than scopolamine, it is hard to entirely exclude the role of muscarinic receptors in the effects of galantamine, as nAChR antagonists not only block the function of nAChRs but also eliminate the desensitization of nAChR-induced increase of the function of muscarinic receptors (Wan et al, 2003).

The mechanism of learning and memory impairments in the $\mathrm{A} \beta_{25-35}$-injected mice is still not clear. Harkany et al (1998) have shown that bilateral injection of $\mathrm{A} \beta$ $\left[\mathrm{Phe}\left(\mathrm{SO}_{3} \mathrm{H}\right)^{24}\right]_{25-35}$ peptide, a metabolically stable analog of $\mathrm{A} \beta_{25-35}$, into the rat nucleus basalis magnocellularis causes a reduction of cortical acetylcholinesterase-positive projections. In PC12 cells, $\mathrm{A} \beta$ has been found to suppress the expression of nAChRs, such as the decrease of nAChRbinding sites, subunit proteins, and mRNA levels (Guan et al, 2001, 2003). In the present study, in vivo microdialysis experiment revealed that the basal extracellular level of dopamine in the hippocampus of $\mathrm{A} \beta_{25-35}$-injected mice was decreased compared to that of saline-injected mice. Furthermore, we have previously demonstrated by in vivo microdialysis that continuous infusion of $\mathrm{A} \beta_{1-40}$ markedly decreased high potassium- and nicotine-induced release of acetylcholine and dopamine in the hippocampus, cerebral cortex, and striatum, respectively (Itoh et al, 1996). These findings confirmed that the deposition of $\mathrm{A} \beta$ in the brain is in some way related to the impairment of cognition and cholinergic-dopaminergic degeneration and suggest that dysfunctions of cholinergic and dopaminergic systems are responsible, at least in part for the $\mathrm{A} \beta$-induced learning and memory deficits.

It has been reported that galantamine $(10 \mu \mathrm{M}, 4$ days $)$ dose not significantly affect the mRNA level and protein expression of $\mathrm{nAChR}$ subunits (Kume et al, 2005). Galantamine increases cholinergic function mainly in two ways: (a) increasing the concentration of acetylcholine through a competitive reversible inhibition of acetylcholine hydrolysis by acetylcholinesterase, which will increase the extracellular acetylcholine concentration and (b) allosteric modulation of nAChRs (Woodruff-Pak and Santos, 2000). The potential cognitive improving effects of galantamine on Alzheimer's disease may be related, in part, to the stimulation of dopamine neurotransmission in addition to its enhancing effects on cholinergic systems by inhibition of acetylcholinesterase. The in vivo microdialysis experiment showed that galantamine significantly increased the dopamine release in the hippocampus of saline- and $\mathrm{A} \beta_{25-35^{-}}$ injected mice. The effect of nicotine on dopamine release 
was strengthened by galantamine, at their noneffective doses, and antagonized by mecamylamine. Accordingly, it is plausible that galantamine ameliorates the $\mathrm{A} \beta_{25-35}$-induced learning and memory deficits by activating nAChR, and thereby stimulates release of dopamine in the brain. Further, we found that the improving effects of galantamine were prevented by SCH-23390, a dopamine-D1 receptor antagonist, and sulpiride, a dopamine-D2 receptor antagonist. Taken together, our results suggest that these hippocampus-dependent performance in these tasks were impaired by $\mathrm{A} \beta_{25-35}$ infusion as the result of failure of $\mathrm{nAChR}$ and dopamine responses, as the hippocampus is involved in the object recognition behavior (Rampon et al, 2000; Hammond et al, 2004) and the contextual fear conditioning (Daumas et al, 2004). These findings provide the first in vivo evidence that galantamine augments dopaminergic neurotransmission within the hippocampus through the allosteric activation of nAChR.

The deficit in the nAChR-dopaminergic systems is one of the facets of general degeneration in neurons induced by $\mathrm{A} \beta_{25-35}$ treatment. The cognitive improving effects of galantamine at the present dose depend on the function of nAChR-dopaminergic systems, therefore the effects are prone to be blocked by the antagonism of the nAChRdopaminergic systems. However, in the normal animals, neurons and their functions are almost intact: the functions and the homeostasis in neurons slightly impaired by the antagonists of the nAChR-dopaminergic systems at relatively low doses, as they can somewhat be restored by compensating mechanisms that are not very clear until now.

Because the improving-effects of galantamine on the cognitive dysfunction induced by $\mathrm{A} \beta_{25-35}$ i.c.v. injection may be mediated through the activation of, at least in part, dopaminergic systems, we postulate that galantamine may activate dopaminergic neurotransmission in Alzheimer's disease by augmenting the activation of nAChR. This is supported by the fact that galantamine potentiated the hippocampal dopamine release in the $\mathrm{A} \beta_{25}$-35-injected model of Alzheimer's disease, and the effects of galantamine on cognition and dopamine release was antagonized by an AChR antagonist, mecamylamine. Because the dopaminergic dysfunction has been implicated in the progress of Alzheimer's disease, dopaminergic agents may be beneficial in the treatment, and enhancement of dopamine release may be part of the mechanisms underlying the therapeutic benefit of galantamine. The results also suggest that in addition to Alzheimer's disease, galantamine may be valuable in the treatment of other diseases involving the dysfunction of dopaminergic systems, such as Parkinson's disease and neuropsychiatric dysfunctions including anxiety, depression, apathy, and psychosis.

\section{ACKNOWLEDGEMENTS}

We are grateful to the Janssen Pharmaceutical KK for donating galantamine. This work was supported, in part, by Grants-in-Aid for Scientific Research from the Japan Society for the Promotion of Science (14370031) (15922139) (16922036) (17390018), for Scientific Research on Priority Areas on 'Elucidation of glia-neuron network mediated information processing systems' from Ministry of Educa- tion, Culture, Sports, Science and Technology (16047214), for Funds from Integrated Molecular Medicine for Neuronal and Neoplastic Disorders (21st Century COE program), for the Japan Brain Foundation, for the Mitsubishi Pharma Research Foundation and, for an SRF Grant for Biomedical Research.

\section{REFERENCES}

Assal F, Cummings JL (2002). Neuropsychiatric symptoms in the dementias. Curr Opin Neurol 15: 445-450.

Burghaus L, Schutz U (2000). Quantitative assessment of nicotinic acetylcholine receptor proteins in the cerebral cortex of Alzheimer patients. Brain Res Mol Brain Res 76: 385-388.

Daumas S, Halley H, Lassalle JM (2004). Disruption of hippocampal CA3 network: effects on episodic-like memory processing in C57BL/6J mice. Eur J Neurosci 20: 597-600.

Eisele JL, Bertrand S, Galzi JL, Devillers-Thiery A, Changeux JP, Bertrand D (1993). Chimaeric nicotinic-serotoninergic receptor combines distinct ligand binding and channel specificities. Nature (Lond) 366: 479-483.

Enomoto T, Noda Y, Mouri A, Shin EJ, Wang D, Murai R et al (2005). Long-lasting impairment of associative learning is correlated with a dysfunction of $\mathrm{N}$-methyl-D-aspartate-extracellular signaling-regulated kinase signaling in mice after withdrawal from repeated administration of phencyclidine. Mol Pharmacol 68: 1765-1774.

Erkinjuntti T (2002). Treatment options: the latest evidence with galantamine (Reminyl). J Neurol Sci 203-204: 125-130.

Geerts H (2005). Indicators of neuroprotection with galantamine. Brain Res Bull 64: 519-524.

Geerts H, Guillaumat PO, Grantham C, Bode W, Anciaux K, Sachak $S$ (2005). Brain levels and acetylcholinesterase inhibition with galantamine and donepezil in rats, mice and rabbits. Brain Res 1033: 186-193.

Guan ZZ, Miao H, Tian JY, Unger C, Nordberg A, Zhang X (2001). Suppressed expression of nicotinic acetylcholine receptors by nanomolar beta-amyloid peptides in PC12 cells. J Neural Transm 10: 1417-1433.

Guan ZZ, Yu WF, Shan KR, Nordman T, Olsson J, Nordberg A (2003). Loss of nicotinic receptors induced by beta-amyloid peptides in PC12 cells: possible mechanism involving lipid peroxidation. J Neurosci Res 71: 397-406.

Hammond RS, Tull LE, Stackman RW (2004). On the delaydependent involvement of the hippocampus in object recognition memory. Neurobiol Learn Mem 82: 26-34.

Harkany T, O'Mahony S, Kelly JP, Soos K, Toro I, Penke B et al (1998). Beta-amyloid $\left(\mathrm{Phe}\left(\mathrm{SO}_{3} \mathrm{H}\right)^{24}\right) 25-35$ in rat nucleus basalis induces behavioral dysfunctions, impairs learning and memory and disrupts cortical cholinergic innervation. Behav Brain Res 90: 133-145.

Hefco V, Yamada K, Hefco A, Hritcu L, Tiron A, Nabeshima T (2004). The interaction between the cholinergic and dopaminergic system in learning and memory process in rats. Rom J Physiol 41: 21-30.

Itoh A, Nitta A, Nadai M, Nishimura K, Hirose M, Hasegawa T et al (1996). Dysfunction of cholinergic and dopaminergic neuronal systems in $\beta$-amyloid protein-infused rats. J Neurochem 66: 1113-1117.

Kamei H, Nagai T, Nakano H, Togan Y, Takayanagi M, Takahashi $\mathrm{K}$ et al (2006). Repeated methamphetamine treatment impairs recognition memory through a failure of novelty-induced ERK 1/ 2 activation in the prefrontal cortex of mice. Biol Psychiatry 59: 75-84.

Kume T, Sugimoto M, Takada Y, Yamaguchi T, Yonezawa A, Katsuki $\mathrm{H}$ et al (2005). Up-regulation of nicotinic acetylcholine 
receptors by central-type acetylcholinesterase inhibitors in rat cortical neurons. Eur J Pharmacol 527: 77-85.

Levin ED, Simon BB (1998). Nicotinic acetylcholine involvement in cognitive function in animals. Psychopharmacology (Berl) 138: 217-230.

Lockhart BP, Benicourt C, Junien JL, Privat A (1994). Inhibitors of free radical formation fail to attenuate direct $\beta$-amyloid25-35 peptide-mediated neurotoxicity in rat hippocampal cultures. J Neurosci Res 39: 494-505.

Maelicke A, Albuquerque EX (2000). Allosteric modulation of nicotinic acetylcholine receptors as a treatment strategy for Alzheimer's disease. Eur J Pharmacol 393: 165-170.

Maelicke A, Schrattenholz A, Samochocki M, Radina M, Albuquerque EX (2000). Allosterically potentiating ligands of nicotinic receptors as a treatment strategy for Alzheimer's disease. Behav Brain Res 113: 199-206.

Maurice T, Lockhart BP, Privat A (1996). Amnesia induced in mice by centrally administered beta-amyloid peptides involves cholinergic dysfunction. Brain Res 706: 181-193.

Nagai T, Yamada K, Kim HC, Kim YS, Noda Y, Imura A et al (2003). Cognitive impairment in the genetic model of aging klotho gene mutant mice: a role of oxidative stress. FASEB J 17: $50-52$.

Nordberg A (2001). Nicotinic receptor abnormalities of Alzheimer's disease: therapeutic implications. Biol Psychiatry 49: $200-210$.

Palmer AM (2002). Pharmacotherapy for Alzheimer's disease: progress and prospects. Trends Pharmacol Sci 23: 426-433.

Paxinos G, Franklin KBJ (2004). The Mouse Brain in Stereotaxic Coordinates, Compact, 2nd edn. Elsevier Academic Press: San Diego, USA.
Rampon C, Tang YP, Goodhouse J, Shimizu E, Kyin M, Tsien JZ (2000). Enrichment induces structural changes and recovery from nonspatial memory deficits in CA1 NMDAR1-knockout mice. Nat Neurosci 3: 238-244.

Santos MD, Alkondon M, Aracava Y, Eisenberg HM, Maelicke A, Albuquerque EX (2002). The nicotinic allosteric potentiating ligand galantamine facilitates synaptic transmission in the mammalian central nervous system. Mol Pharmacol 61: 1222-1234.

Schroder H, Giacobini E, Struble RG, Zilles K, Maelicke A (1991). Nicotinic cholinoceptive neurons of the frontal cortex are reduced in Alzheimer's disease. Neurobiol Aging 12: 259-262.

Sharp BM, Yatsula M, Fu Y (2004). Effects of galantamine, a nicotinic allosteric potentiating ligand, on nicotine-induced catecholamine release in hippocampus and nucleus accumbens of rats. J Pharmacol Exp Ther 309: 1116-1123.

Turner TJ (2004). Nicotine enhancement of dopamine release by a calcium-dependent increase in the size of the readily releasable pool of synaptic vesicles. J Neurosci 24: 11328-11336.

Van Dam D, De Deyn PP (2006). Cognitive evaluation of diseasemodifying efficacy of galantamine and memantine in the APP23 model. Eur Neuropsychopharmacol 16: 59-69.

Wan Q, Luo ZP, Wang H (2003). Muscarinic receptor activities potentiated by desensitization of nicotinic receptors in rat superior cervical ganglia. Acta Pharmacol Sin 24: 657-662.

Woodruff-Pak DS, Santos IS (2000). Nicotinic modulation in an animal model of a form of associative learning impaired in Alzheimer's disease. Behav Brain Res 113: 11-19.

Woodruff-Pak DS, Vogel III RW, Wenk GL (2003). Mecamylamine interactions with galantamine and donepezil: effects on learning, acetylcholinesterase, and nicotinic acetylcholine receptors. Neuroscience 117: 439-447. 